\title{
DE LA SELVA Y LAS SALINAS. \\ HISTORIA SOCIAL DE DOS PUEBLOS-EMPRESA \\ EN EL ORIENTE DE YUCATÁN (1930-1970)
}

\author{
InÉs CoRTÉs CAMPOS \\ Centro Peninsular en Humanidades y Ciencias Sociales, UNAM
}

Resumen: Aunque en últimos años la industria turística ha sido una fuerza decisiva en la organización del sur y el oriente de la Península de Yucatán, antes de su irrupción se desarrollaron varias actividades centradas en la obtención de materias primas, las cuales tuvieron un gran impacto en la conformación moderna de dicho espacio social. Con miras a contribuir al estudio de la historia reciente del sureste de la península yucateca, este artículo presenta la historia social de dos poblaciones dedicadas a la producción industrial de sal marina y de maderas preciosas, actividades que durante buena parte del siglo xx constituyeron vectores importantes en la explotación del área mencionada. El propósito principal es problematizar los procesos modernos de construcción y transformación regional del oriente de la Península de Yucatán a la luz del surgimiento y devenires de las dos poblaciones.

PalabRas ClaVE: región, pueblo-empresa, sal, empresa forestal, Yucatán.

ABSTRACT: Although the tourism industry has been a major force in organizing the South and East of the Yucatan Peninsula in recent years, before its irruption several activities focused in obtaining raw materials were developed. These activities had a great impact on the formation of this modern social space. In order to contribute to the study of the recent history of the Southeast of the Yucatan Peninsula, this paper presents the social history of two populations engaged in industrial production of sea salt and precious woods, activities which for most of the twentieth century constituted important vectors in the exploitation of the mentioned area. The main purpose is to discuss modern construction processes and regional transformation of the Eastern Yucatan Peninsula in light of the rise and changes of the two populations.

KEYwORDs: region, company-town, salt, forestry company, Yucatan.

RECEPCIÓn: 5 de marzo de 2013.

ACEPTACIÓN: 10 de junio de 2013. 



\title{
DE LA SELVA Y LAS SALINAS. HISTORIA SOCIAL DE DOS PUEBLOS-EMPRESA EN EL ORIENTE DE YUCATÁN (1930-1970) ${ }^{1}$
}

\author{
InÉS CoRTÉs CAMPOS \\ Centro Peninsular en Humanidades y Ciencias Sociales, UNAM
}

\section{Introducción}

El artículo analiza la conformación social e histórica de dos poblaciones que surgieron en el oriente de la península yucateca a fines de la década de 1930 . Tales pueblos son Las Coloradas, situado en el extremo de la costa este de la entidad, y Colonia Yucatán, ubicado a 40 kilómetros de la cabecera de Tizimín, el municipio más grande en el oriente del estado de Yucatán (figura 1). Ambos pueblos comparten el haber sido fundados casi en el mismo momento y con el mismo propósito, a saber, la explotación industrial de los abundantes recursos naturales presentes en la zona, la sal marina en el caso del primer pueblo, y las maderas preciosas, en el segundo. A pesar de las diferencias en sus trayectorias -mientras que la explotación de sal de Las Coloradas se mantiene vigente y constituye una de las industrias salineras más extensas de México, las actividades de lo que en otro tiempo fue la próspera empresa maderera de Colonia Yucatán cesaron por completo en la década de 1990 - , resulta sumamente llamativa la semejanza de sus procesos formativos.

Las dos poblaciones tuvieron en común un elemento axial en su construcción, a saber, su estructuración como pueblos-empresa. Este concepto describe aquellos espacios sociales cuyo surgimiento está asociado a la creación de una industria, y cuyas dinámicas son reguladas, en lo fundamental, por el sector patronal que la controla. Aunque no es una característica universal, muchos pueblos-empresa comparten el hecho de carecer de orígenes antiguos, ya que en general fueron fundados como efecto de la concentración reciente de población

\footnotetext{
${ }^{1}$ Esta investigación fue desarrollada durante la estancia posdoctoral que llevé a cabo entre 2012 y 2013 en el Centro Peninsular en Humanidades y Ciencias Sociales (CEPHCIS) de la Universidad Nacional Autónoma de México (UNAM), como becaria del Programa de Becas Posdoctorales de la propia Universidad, y con la asesoría del Dr. Mario Humberto Ruz Sosa. Deseo hacer patente mi gratitud a la UNAM, al CEPHCIS, al Dr. Ruz y también a la Dra. Sandra Lucía Ramírez Sánchez, del CEPHCIS, por las facilidades otorgadas para la realización de esta investigación. Quiero expresar, asimismo, mi sincero agradecimiento a los pobladores de Las Coloradas y de Colonia Yucatán, cuyos testimonios dan cuerpo a este escrito.
} 

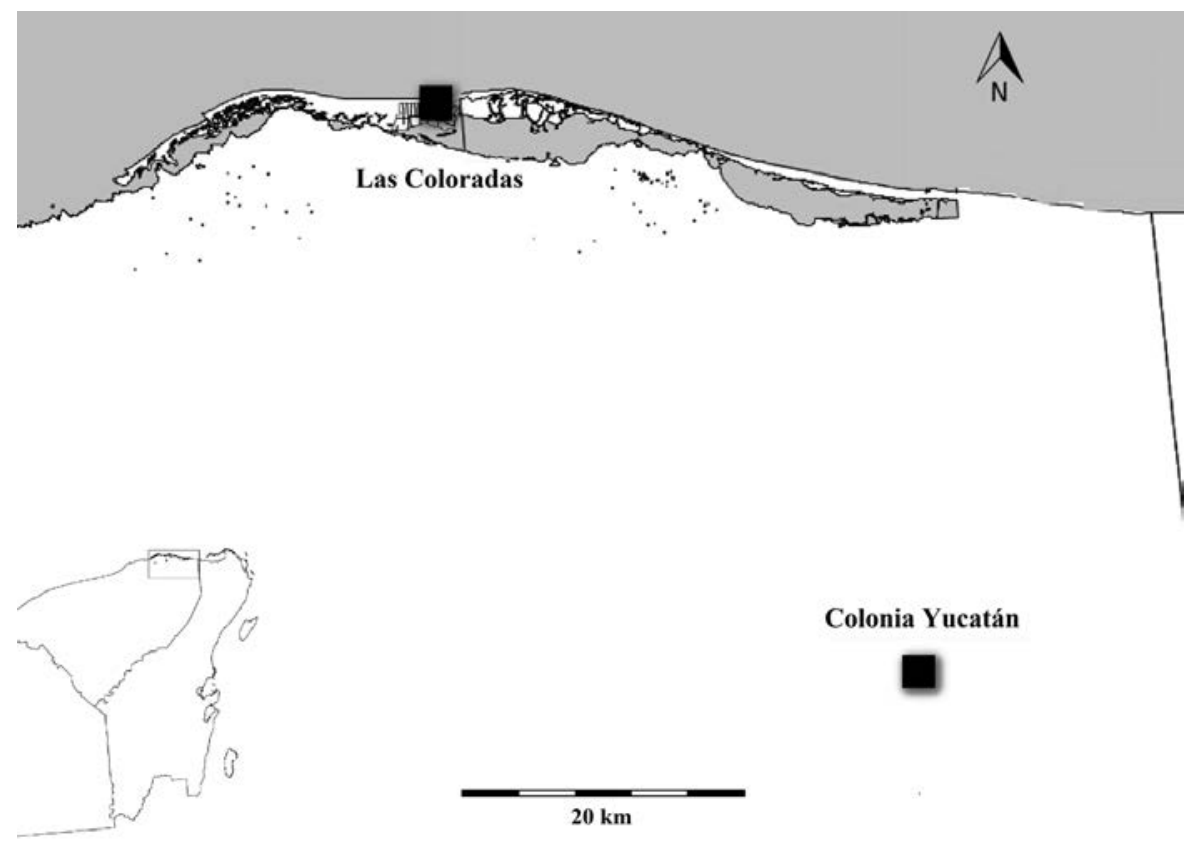

\section{Colonia Yucatán}

FIGURA 1

trabajadora en aquellos sitios cuya riqueza natural o ubicación resultaron favorables al establecimiento de operaciones de gran escala. $\mathrm{O}$ bien, en otros casos se trata de poblaciones de raíces antiguas que en algún momento de su historia moderna fueron penetradas por la implantación de una industria.

En cualquier caso, las poblaciones formadas bajo estos sistemas suelen ser habitadas casi privativamente por quienes trabajan para la industria, y en ellas los medios para ganarse la vida son sumamente limitados, en buena medida porque los patrones procuran mantener esta condición como parte de un esquema tendiente a reducir los costos de la producción, pero también para garantizar el mayor control social sobre los trabajadores y los recursos del lugar. Ligado a esto, los pueblos-empresa suelen estar bajo un gran aislamiento. ${ }^{2}$

Durante el periodo que transcurrió entre las décadas de 1930 y 1970 —las épocas de surgimiento y expansión de las industrias salinera y forestal en los dos sitios-, las trayectorias de Las Coloradas y de Colonia Yucatán compartían éstas

\footnotetext{
${ }^{2}$ En México, algunos ejemplos de este tipo de espacios sociales - también conocidos como enclaves o company towns - los constituyen los pueblos mineros del norte del país, al igual que ciertos complejos industriales, como Las Truchas, en Michoacán. Para autores como Francisco Zapata, el enclave es un arraigado modelo de explotación del trabajo y de los recursos naturales en América Latina, tan importante como en su momento lo fue el sistema de haciendas (Zapata, 1977; Sariego, 1988).
} 
y otras características, especialmente en cuanto al tipo de dominio que los empresarios llegaron a establecer sobre la población. Al sustentarse en formas de control sumamente autoritarias, los patrones consiguieron un aprovechamiento desmedido del trabajo, y abonaron en la explotación monopólica de los recursos naturales.

Pero más allá de sus semejanzas, y desde luego sin obviar sus diferencias, es notable la peculiaridad de las dos poblaciones en el desarrollo moderno de la Península de Yucatán, especialmente por el hecho de que surgieron en el mismo espacio regional, el oriente de la misma, que junto con el sur compone la región histórica conocida como montaña.

Partiendo de estas observaciones, el objetivo del presente artículo es identificar algunos de los factores que explicarían la particular configuración de estas dos poblaciones durante el periodo mencionado, y su presencia específica en dicho espacio regional. Aunque podríamos suponer que la adopción de sistemas fue un proceso de gran importancia - como ocurrió con las plantaciones y haciendas en diversos contextos, donde por su eficacia el mismo esquema de dominio fue repetido una y otra vez en diferentes sitios-, aquí preferimos indagar el papel que tuvo la trayectoria histórica de la montaña en el surgimiento y ubicación de estas singulares poblaciones.

Con el propósito de acercarnos a las especificidades sociales de Las Coloradas y Colonia Yucatán, sugerimos que ambas poblaciones integraron una microrregión de la montaña, al menos durante el tiempo estudiado. Consideramos que es posible reconocer su integración como microrregión a partir de tres factores. El primero es el hecho de que las dos explotaciones surgieron en forma excepcional al desarrollo general de la montaña en el periodo posrevolucionario, ya que un sector empresarial se convirtió en el principal rector de las inversiones, y no la iniciativa estatal que por entonces se robustecía en la región. El segundo es la concreción de amplios proyectos de industrialización que no tuvieron parangón en otras zonas de la montaña. Y el tercero lo constituye la centralidad de los empresarios en lo concerniente a la organización social y del trabajo en las dos poblaciones. ${ }^{3}$

Dedicamos un apartado al análisis de cada uno de estos factores, presentando antes una breve problematización sobre la construcción de la montaña como región y los imaginarios históricos que contribuyeron a ello, enfatizando su relación con la conformación de los dos pueblos-empresa.

\section{La montaña}

Referirse al sur y al oriente de la Península de Yucatán como montaña es una práctica discursiva que ha trascendido su origen colonial —asociado a la resis-

\footnotetext{
${ }^{3}$ En esta exposición dejamos de lado los procesos mercantiles que contribuyeron a la expansión de las dos industrias.
} 
tencia indígena al dominio español—, y en la actualidad tiene cierta vigencia entre quienes habitan dicho espacio social, sobre todo los ancianos y personas de edad mediana. En los discursos posteriores a la segunda mitad del siglo xx, el término montaña describe los altos y extensos montes o selvas que, hasta antes de la década de 1960, dominaron el paisaje del sureste yucateco, y también alude a la lejanía y el despoblamiento que según las experiencias vividas de muchas personas caracterizaron a este espacio. La permanencia del término es notable si se toman en cuenta las numerosas transformaciones de las que la región ha sido sujeto en las últimas décadas, y que han implicado el desmantelamiento de la selva y su poblamiento reciente. ${ }^{4}$

Acercarnos a algunos componentes de este antiguo imaginario de la montaña, al igual que a los diversos procesos históricos que lo convirtieron en el soporte ideológico de la conformación del sur y oriente de Yucatán como región, es útil para identificar ciertas fuerzas que intervinieron en la construcción de Las Coloradas y Colonia Yucatán como pueblos-empresa y en su integración como microrregión.

La antigua concepción de la montaña tiene orígenes que se remontan al periodo colonial, cuando miles de mayas fugitivos del dominio español huyeron hacia las espesas selvas, sabanas y costas allende Mérida. El sureste yucateco no era un espacio totalmente deshabitado a la llegada de los españoles, pero el hecho de que la población maya tendiera a concentrarse en el norte de Yucatán desde antes de la conquista y después de ella implicó que dicho territorio permaneciera fuera del dominio español durante un largo periodo. Incluso, entre fines del siglo xVI y fines del xvIII era posible distinguir a esta área como la zona de emancipación de los mayas yucatecos, la cual se extendía desde la laguna de Yalahau, en el nororiente de la península, hasta el sureste del río Hondo, incluyendo la frontera con la laguna de Términos. Es decir, buena parte de los actuales estados mexicanos de Quintana Roo, Campeche y Tabasco, y una porción del norte de Belice (Bracamonte y Sosa, 2001: 59). Baste con mencionar que la región fue el bastión de la rebelión indígena de 1847, episodio conocido como Guerra de Castas.

El largo dominio indígena sobre la zona y el éxito de su rechazo al control de los españoles, primero, y al liberalismo político del gobierno yucateco y de los proyectos mexicanos de nación, después, fueron la base de la construcción de un imaginario que retrataba a la montaña como una tierra hostil e incivilizada. Particularmente arraigada durante la Guerra de Castas, ésta era la visión de las élites blancas, para quienes la guerra significó una confrontación entre barbarie y civilización. Es notable que algunos aspectos de este imaginario pervivieran aun cuando los empresarios salineros y madereros del siglo xx avanzaron en pos

\footnotetext{
${ }^{4}$ Transformaciones relacionadas con la penetración del estado mexicano, la irrupción de la industria turística en los espacios costeros, y la multiplicación de pequeñas poblaciones rurales a partir de los años sesenta, como efecto de la reforma agraria. En el trabajo de Pedro Bracamonte (2001) puede encontrarse una amplia discusión sobre el origen de la palabra montaña y su relación con la construcción histórica de la región durante la Colonia.
} 
de la explotación de los recursos naturales de la zona, y como señalaremos más adelante, esta continuidad ideológica se convirtió en un importante factor que, desde la racionalidad patronal, explicaba sus autoritarias formas de control social sobre los trabajadores y la población en general.

Durante la Guerra de Castas, el control de los indígenas sobre los recursos naturales de la zona fue vital para mantener su prolongado atrincheramiento en la montaña. Varios estudios han documentado la importancia de la explotación forestal y del chicle para el soporte de la rebelión de 1847, principalmente a través del comercio con los británicos (Forero y Redclift, 2006; Macías, 1999; Villalobos, 1993). El que la mayoría de estos procesos mercantiles hubieran tenido lugar a través del contrabando - debido a la carencia de regulación por parte del gobierno mexicano- también trazó una línea histórica importante en el desarrollo de la región y en el imaginario sobre ella. En las memorias vivas y los relatos escritos sobre la fundación de los dos pueblos-empresa el contrabando es descrito como una amenaza que debía ser combatida a toda costa por los empresarios.

El dominio indígena sobre la región solamente fue mermado por el control militar del estado mexicano a partir de 1901. Sin embargo, desde 1870, la llegada de empresarios yucatecos procedentes del centro y norte del país y del extranjero constituyó un importante avance sobre el territorio indígena. Durante el porfiriato, varios empresarios consiguieron concesiones y arrendamientos para la explotación del palo de tinte, las maderas preciosas, la sal y el chicle, o bien permisos de deslinde de terrenos baldíos. Como parte de este desarrollo surgieron la Compañía Agrícola El Cuyo y Anexas, en 1876, y la Compañía Colonizadora de la Costa Oriental, en 1889, entre otras (Villalobos, 1993: 91-92 y 102), cuyos asentamientos se convirtieron en las únicas zonas "civilizadas" de la montaña, y constituyeron los primeros pasos en la colonización y recuperación del espacio en manos de los indígenas. Precisamente, las explotaciones salinera y forestal de Las Coloradas y de Colonia Yucatán se desarrollaron en los territorios ocupados por estas empresas.

Para poner en marcha sus actividades, estas empresas requirieron de un gran conjunto de trabajadores. Aunque los pueblos veracruzanos y los beliceños aportaron numerosos hombres, sobre todo para la producción de chicle, parece que paulatinamente fueron incorporándose los yucatecos. Muchos de ellos eran campesinos empobrecidos y sin tierra, provenientes de las plantaciones henequeneras del noreste de Yucatán, aunque poco a poco también se sumaron indígenas originarios de las poblaciones mayas rebeldes. ${ }^{5}$ En cualquier caso, las dificultades para el acceso a la tierra constituyeron un importante factor que incidió en la conformación del moderno sector trabajador del oriente de Yucatán. Para muchos

\footnotetext{
${ }^{5}$ De acuerdo con Herman Konrad (1987: 485), “la economía chiclera constituyó el factor más importante en la reintegración de los mayas rebeldes”, primero organizados por líderes indígenas y luego en forma de cooperativas.
} 
de estos hombres la producción de chicle y el corte de maderas preciosas eran actividades sumamente atractivas, debido a la alta remuneración monetaria que en ellas se ofrecía, en comparación con lo que podían obtener como jornaleros agrícolas. Quizá como efecto de este proceso, asociado a la expansión de los capitales en la región, comenzaba a arraigarse un nuevo imaginario de la montaña que la describía como una tierra de bonanza, poniendo en relieve las grandes sumas de dinero que, supuestamente, ahí podían obtenerse. Desde las ópticas patronales, pero también desde las perspectivas de muchos trabajadores de Las Coloradas y Colonia Yucatán, esta consideración llegó a constituir una de las principales justificaciones de los denodados niveles de explotación que los empresarios llegaron a ejercer sobre cientos de obreros.

Este estado de cosas en el que las empresas protagonizaban el aprovechamiento de los principales recursos naturales del sureste de Yucatán se mantuvo hasta que el presidente Lázaro Cárdenas del Río retiró las concesiones forestales y chicleras, en la década de 1930, con el propósito de concretar los repartos agrarios en el territorio de Quintana Roo. Sin embargo, esto no implica que los grandes latifundios del porfiriato hubieran desaparecido completamente, pues, por mencionar un ejemplo, la compañía El Cuyo y Anexas (con linderos entre Yucatán y el territorio de Quintana Roo) mantuvo buena parte de sus colindancias, y no fue afectada sino en el transcurso de varios repartos agrarios, particularmente durante la década de 1960 . Como veremos enseguida, la continuidad de estos problemas de concentración de la tierra, pero bajo el cobijo del estado posrevolucionario, constituyó una de las condiciones más importantes en el surgimiento de las explotaciones forestales y salineras de Colonia Yucatán y de Las Coloradas (Villalobos, 1993: 109).

\section{Empresarios salineros y forestales}

Las problemáticas y procesos ideológicos arriba descritos contribuyeron a la conformación de la montaña como región histórica. Sin embargo, no es posible hablar de ella como un espacio social ni históricamente homogéneo. Desde este punto de vista proponemos que la conformación de Las Coloradas y Colonia Yucatán como microrregión salinera y forestal es parte de los procesos de diferenciación interna de la montaña moderna. ${ }^{6}$

Las acciones de los empresarios Medina y Roche en el fomento a las actividades forestal y salinera, respectivamente, permiten ubicarlos como los principales artífices de esta microrregión en el oriente de Yucatán. Hubo varios procesos que pudieron haber favorecido la concentración de su actividad en una zona específica de la montaña, y en este apartado reflexionamos sobre algunos de ellos. En particular,

\footnotetext{
${ }^{6}$ A propósito de la heterogénea composición de la montaña, el trabajo de Bracamonte (2001: 29) describe la diversidad de poblaciones que se asentaron en ella durante la Colonia.
} 
consideramos que un problema relevante fue la conjugación de la persistencia del añejo problema de concentración de la propiedad de la tierra, con el proyecto posrevolucionario de combate a los latifundios, que en teoría iba a contrapelo de ello. A esto debe aunarse los proyectos de corte nacionalista y desarrollista orientados a ampliar las bases de la economía del país a través de la industrialización, los cuales fueron puestos en marcha en el tiempo cuando surgieron las dos empresas.

Para acercarnos a estos procesos es necesario partir de las gestiones del presidente Cárdenas. Tengamos en consideración que una de las principales directrices de su sexenio la constituyeron los repartos agrarios, mediante la expropiación de las grandes fincas. A tal fin, Cárdenas condujo en la Península de Yucatán la afectación de las plantaciones de henequén en el noroeste, mientras que en el sureste, como ya mencionamos, retiró las extensas concesiones forestales y chicleras. Con el propósito de mantener el aprovechamiento de los recursos naturales pero sin la injerencia de empresarios, Cárdenas conformó ejidos, cooperativas y reservas forestales y chicleros que quedaron bajo la observancia del estado. Esto permitió que en las décadas siguientes la burocracia estatal se posicionara como eje rector en la organización del espacio y del trabajo social en la región, siendo uno de los principales efectos de ello la paulatina neutralización del control indígena en ella. Tomando en cuenta este avance del estado mexicano, no sólo sobre el territorio de los mayas rebeldes, sino también en aparente desafío a la inversión privada, resulta curiosa la emergencia de los empresarios Roche y Medina como industriales salineros y forestales en la montaña en este contexto.

Un importante elemento detrás de este curioso proceso fue el hecho de que Cárdenas y los presidentes que le sucedieron crearon condiciones que favorecieron la concentración de capitales en torno a la explotación de ciertos recursos naturales.

Respecto a la sal en 1935, Cárdenas declaró que la producción del mineral sería un asunto de interés público, quizá debido a que previó el apogeo salinero que resultaría del crecimiento de las industrias petrolera y petroquímica mexicana -impulsadas por él mismo-, en las que la sal constituye una importante materia prima para la extracción del crudo y su transformación. Con la finalidad de promover la producción del mineral decretó la formación de cooperativas y de organizaciones de productores. Igualmente, procuró la creación de un organismo que reglamentara los volúmenes de producción del mineral y sus precios - la Asociación Nacional de Productores de Sal (ANP)—, y estableció la fiscalización de su venta a través del impuesto a la sal. Estas declaratorias facilitaron el ingreso de los empresarios Roche en la producción del mineral. ${ }^{7}$

Los hermanos Joaquín y Eduardo Roche Martínez — fundadores de Industria Salinera de Yucatán S. A. (ISYSA), la empresa salinera de Las Coloradas-fueron

\footnotetext{
${ }^{7}$ Este mandato tuvo su antesala en un acuerdo de 1933, mediante el cual las costas y playas del Golfo de México y del Océano Pacífico fueron declaradas reservas nacionales para la producción de sal (Diario Oficial de la Federación, 8 de junio de 1935 y 26 de septiembre de 1933).
} 
hijos de un pequeño comerciante originario del puerto Progreso, Yucatán. Durante un tiempo se dedicaron al comercio de mercancías diversas, y tras relacionarse con un productor yucateco de sal, en la década de 1930, los Roche comenzaron a explotar los charcos salinos del pueblo costero de San Crisanto, en la costa central de Yucatán, y fundaron la empresa Salinas del Mayab, que por entonces movilizaba anualmente unos pocos centenares del mineral. A comienzos de 1940, Salinas del Mayab se unió a la cooperativa Fraternidad — creada en la mencionada coyuntura, y que agrupaba a numerosos productores yucatecos de sal de las costas noroeste y central de la entidad- para integrar la organización conocida como Unión de Salineros del Sureste. En algún momento de la década, los hermanos Roche llegaron a presidir dicha organización, desde la cual pudieron gestionar recursos y mercados para su naciente explotación salinera.

Refiriéndonos a la concentración de sus actividades en la costa oriental de Yucatán, hubo arreglos territoriales que favorecieron su localización en esta área específica y no en otro punto del litoral, pese a que varios pueblos de las costas noroeste y central del estado concentraban extensos conjuntos de salinas.

A fines de los años treinta, los hermanos Roche adquirieron un rancho en cuyos terrenos se encontraban varias salinas y se ubicaba dentro de los límites de la mencionada Compañía Agrícola El Cuyo y Anexas, que por entonces permanecía sin afectación alguna. ${ }^{8}$

El hecho de que las salinas hubieran sido parte de esta gran finca dio una importante ventaja a los empresarios, que alentó la concentración de sus actividades en este espacio. Esta ventaja residía en que la particular ubicación de las salinas implicaba la ausencia de población originaria en torno a ellas que reclamara su disfrute, circunstancia que hacía posible que los empresarios pudieran explotarlas sin encontrar mayor competencia por el acceso a ellas.

El estado de las concesiones salineras arroja luz sobre esta situación. Por principio de cuentas, debemos tener en cuenta que la constitución promulgada por el presidente Venustiano Carranza en 1917 estableció que el dominio de las salinas - como el de todos los yacimientos minerales en el país- correspondía a la nación, cancelando así su propiedad privada, y estipulando su disfrute sólo a través de concesiones. Resulta sumamente llamativo que en el apogeo salinero de la década de 1930 se hubieran otorgado más de un centenar de concesiones salineras en las costas noroeste y central de Yucatán, y en cambio sólo unas pocas en el litoral oriental del estado, y ninguna en el territorio de Quintana Roo. Aunque esto definitivamente tiene que ver con el desigual número de salinas presentes en estas distintas geografías, el dato hace suponer que en la costa oriental no era urgente apegarse a la normatividad minera que regulaba la explotación de la sal, como sí lo era en el noroeste. Aparentemente, bastaba

${ }^{8}$ El rancho estaba en propiedad de Antonio González, quien no figuraba entre los socios originales de dicha compañía; es probable que la familia Baduy — por entonces principal accionista de la misma - hubiera vendido una porción de sus tierras a este personaje, de cuyas manos pasó a los hermanos Roche. 
con garantizar la propiedad del predio donde se encontraban las salinas para asegurar su disfrute. La situación es notable si se le compara con la de otros pueblos salineros, como Celestún, donde numerosos personajes de clases alta y media y de extracción popular se disputaban el disfrute de las salinas (Secretaría de Economía, 1933: Anexo).

Así, la debilidad del estado en la afectación de fincas como El Cuyo y Anexas, al igual que la laxitud con que operaban en la montaña las disposiciones posrevolucionarias en torno a las concesiones salineras, y la carencia de población originaria posibilitaron un peculiar arreglo territorial que en las décadas posteriores permitió a los hermanos Roche concentrarse en un punto específico de la costa oriental y operar ahí con gran libertad.

Además de ello, hubo otras condiciones particulares de la montaña que favorecieron este fenómeno. Mediante los recursos obtenidos a partir de una asociación con Morton Salt, gran empresa salinera estadunidense, y de créditos otorgados por la banca estatal NAFINSA (Nacional Financiera) durante el sexenio del presidente Miguel Alemán (1946-1952), los Roche tuvieron el impulso necesario para industrializar sus actividades en Las Coloradas (Roche, 1998). Pese a que de por sí la política económica de Alemán estaba orientada a la industrialización del país, su apoyo a estos empresarios no fue casual. Durante su presidencia, la relación de Alemán con Yucatán estuvo dirigida a menguar las fuerzas regionalistas que la élite henequenera defendía desde mediados del siglo xIx y que se agravaron después de la afectación a sus fincas como efecto de la reforma agraria (Demmers, 1998: 72-73). No teniendo los Roche intereses en el henequén, es probable que el apoyo que recibieron de NAFINSA hubiera sido parte de la estrategia de búsqueda de aliados empresariales por parte de Alemán en su enfrentamiento a los henequeneros.

Procesos de naturaleza semejante posibilitaron que la industria maderera en manos del empresario Alfredo Medina Vidiella concentrara la mayor parte de su explotación en el oriente de Yucatán. ${ }^{9}$

Durante las primeras administraciones posrevolucionarias, los bosques y selvas, al igual que la sal, fueron declarados como un asunto de interés público. Desde la promulgación de la Constitución de 1917 había entrado en boga una suerte de ideología conservacionista de los bosques, a partir de la cual se privilegiaba a las comunidades y pueblos originarios el otorgamiento de los derechos de su explotación. Sin embargo, en los años cuarenta, durante el sexenio del presidente Alemán, la economía nacional fue orientada hacia la construcción de una sólida industria nacional, y este derecho privilegiado se mantuvo en manos de las poblaciones, pero también se crearon condiciones que permitieron el ingreso del sector empresarial, a través de disposiciones que preveían la concesión de

\footnotetext{
${ }^{9}$ Aunque Medina fue el principal artífice de esta industria maderera, contó con numerosos asociados, algunos de ellos foráneos a Yucatán y extranjeros. A fines de la década de 1960, Medina se retiró de la empresa, quedando ésta en manos del empresario yucateco David Perló, quien la controló hasta su cierre en 1990.
} 
los bosques y selvas - ya sea de reservas nacionales o de disfrute comunal- a iniciativas privadas. Éste es el primer elemento que enmarca la entrada de Medina como industrial forestal en la montaña moderna. De hecho, varios autores encuentran en este proceso la principal causa de la subsumisión de numerosas poblaciones en el país a los intereses de las empresas forestales (Boyer, 2007; Garibay, 2008: 96; Macías, 2004), y en ese sentido podríamos decir que el control que Medina llegó a ejercer sobre la población de Colonia Yucatán era, en buena medida, parte del esquema afianzado como parte de la política forestal posrevolucionaria.

Medina Vidiella — nacido de una familia yucateca henequenera que se refugió en Cuba durante la Revolución mexicana - es considerado el fundador de la maderera de Colonia Yucatán. Aunque ésta fue creada en 1941, desde mediados de los años treinta Medina contó con permisos para el corte de maderas en diversos predios del sur y oriente de la Península de Yucatán, las cuales vendía en bruto, sin aserrar, en Mérida. Sin embargo, el verdadero crecimiento de la industria maderera en sus manos fue posible gracias al acceso que consiguió a amplias porciones de selva a través de tres mecanismos: la compra-venta de predios, la obtención de concesiones forestales y el establecimiento de convenios con ejidos (sin autor, 1999: 130-131). ${ }^{10}$

La finca San Enrique de Tizimín fue uno de los espacios más importantes en la explotación maderera de Medina en el oriente de Yucatán, cuya extensión alcanzaba las 97255 ha. Como parte de las afectaciones que resultaron de la reforma agraria en el sexenio de Cárdenas, la finca fue expropiada a sus dueños originales, quedando en posesión del Banco Nacional de Crédito Agrícola S. A. ${ }^{11}$ Conviene destacar que de estas afectaciones se formó, en 1937, el ejido de Kantunilkín, en el territorio de Quintana Roo.

Durante algún tiempo Antonio Baduy —uno de los propietarios de la finca El Cuyo y Anexas- hizo convenios con dicho banco para la explotación de cedro en esa finca, pero en 1942, debido al incumplimiento de las cuotas de producción asignadas, el convenio le fue retirado. Al quedar el predio libre, el Banco lo vendió a Medina, quien lo adquirió en su totalidad, y en él construyó las primeras instalaciones industriales y el núcleo de su explotación maderera. ${ }^{12}$

Además de la compra-venta de este predio, para Medina fue vital la obtención de varias concesiones forestales. Entre 1948 y 1949 el gobierno federal decretó la creación de Unidades de Explotación Forestal en todo el país, mediante las cuales cedió los derechos de su explotación a particulares. Como parte de este desarrollo, en 1949 fue creada en el oriente de Yucatán una Unidad de Explotación Forestal en favor de Maderas del Trópico S. A., Maderas de Yucatán y

${ }^{10}$ AGEY, fondo: poder judicial 1840-1966, sección: primer depto., serie: juzgado 2o de lo civil, caja 274, vol. 274, exp. 8091, 1941.

${ }^{11}$ AGEY, fondo: Municipios, sección: Tizimín, caja 1, vol. 2, exp. 11, 1942, foja 19; AGA, oficina de Yucatán, exp. 23-580, poblado: Colonia Yucatán, 1959, asunto: dotación.

${ }^{12}$ AGEY, fondo: Municipios, sección: Tizimín, caja 1, vol. 2, exp. 11, 1942, foja 19; AGA, id. 
Maderas Laminadas S. A, empresas en propiedad de Medina y sus diversos asociaciados. La Unidad comprendía un área de 1166400 ha, y estaría orientada a la explotación del cedro, con una vigencia de treinta años; de su superficie, 462 mil hectáreas se ubicaban en el Estado de Yucatán, y la parte restante en el territorio de Quintana Roo. Es importante señalar aquí que, a diferencia de los salineros Roche, además de los predios mencionados, Medina contó con otra explotación maderera en Zoh Laguna, Campeche (Medina Vidiella, 1950). ${ }^{13}$

Asimismo, Medina estableció convenios con varios ejidos de la región para la explotación de sus bosques comunales. Primero, en los años cuarenta firmó contratos con los ejidatarios de Kantunilkín para el corte de maderas en las tierras del ejido, y posteriormente, entre los años sesenta y setenta, al agotarse las reservas de cedro en la Unidad Industrial y la finca San Enrique, Medina llegó a convenios con varios de los numerosos ejidos que a partir de los años sesenta fueron creados en la zona para el corte de leña —o "maderas corrientes"- en sus terrenos.

La gran riqueza forestal presente en el oriente de Yucatán posibilitó su explotación industrial, pero hubo arreglos políticos que favorecieron este fenómeno. La gestión del presidente Alemán jugó, de nueva cuenta, un papel relevante, ya que la Unidad Industrial que benefició a la industria maderera de Medina fue creada, precisamente, durante el sexenio de este presidente. El apoyo no fue casual, dada la franca simpatía de Medina por el ala alemanista de la política nacional, y sin duda también guardaba relación con las pugnas antes expuestas entre el presidente y los henequeneros.

En lo expuesto hasta aquí observamos que la presencia de tres diferentes formas de disfrute de la selva - la propiedad privada, la concesión forestal y los ejidos- que coexistieron en el oriente de Yucatán crearon condiciones que contribuyeron al dominio de Medina sobre una gran extensión de la selva.

\section{Nichos industriales en la montaña}

Otro factor que permite trazar la integración de la microrregión salinera forestal en la montaña es la proximidad en el espacio de dos grandes industrias de cuyo tipo y amplitud no se encontraron otras en la región durante varias décadas. En relación con esto, resulta significativo observar que las trayectorias de las dos empresas guardan enormes semejanzas en cuanto a los diversos proyectos de tecnologización realizados por los empresarios, sin duda conectados con los ricos yacimientos salinos y amplias reservas forestales a los que habían conseguido acceso como resultado de los procesos antes descritos.

En los dos casos, a partir de 1940 se presentó un tránsito de métodos manuales o escasamente tecnologizados, basados en el uso intensivo del esfuerzo humano para el corte de maderas y la recolección de sal, a procesos automatizados

${ }^{13}$ Diario Oficial de la Federación, 28 de julio de 1949; AGA, id. 
y dependientes del empleo de motores eléctricos y de diesel, y de maquinaria pesada, los cuales no solamente ampliaron la capacidad de las empresas para obtener las materias primas, sino que también posibilitaron su transformación en productos procesados o acabados, entre ellos diversos tipos de sal, principalmente para uso industrial, al igual que numerosos clases de maderas y derivados (triplay, aglomerados, lambrines, puertas, entre otros).

En cuanto a la empresa maderera, durante los primeros años de su participación en la actividad, Medina se dedicó al corte de rolos de cedro rojo (cedrela odorata) en bruto. Aunque el cedro rojo era la madera más explotada en el sureste de Yucatán, se le consideraba un material duro sin mejor potencial que la fabricación de durmientes. Por ello Medina buscaba introducir nuevos usos para el cedro y expandir su mercado. ${ }^{14}$

Durante los primeros años utilizó el sistema común en la región, basado en el empleo de contratistas especializados en el corte de madera, la mayoría originarios de Tizimín. El proceso productivo era poco tecnificado. Los taladores cortaban los árboles con hacha, mientras que otros hombres trasladaban los rolos desde el lugar del corte hasta los llamados tumbos, utilizando la tracción de mulas y bueyes; conviene destacar aquí que el corte de maderas se realizaba solamente durante medio año, en tiempos de secas (entre octubre y marzo). Las trozas de madera se mandaban a Tizimín, y desde ahí a Mérida en tren, donde serían aserradas. ${ }^{15}$

A partir de los años cuarenta, Medina procuró la tecnificación y automatización de los procesos productivos, con el propósito de manufacturar productos transformados o acabados. Por una parte, consiguió que el arraigado sistema de tumba de árboles mediante hacha fuera sustituido por motosierras, las cuales permitían un mejor aprovechamiento de los árboles. Y, por otra parte, encauzó la construcción de fábricas para la transformación de los enormes volúmenes de madera que el uso de las sierras permitía obtener. ${ }^{16}$ Estas fábricas utilizaban

\footnotetext{
${ }^{14}$ Aunque en muchas memorias escritas y relatos orales se considera que Medina tuvo el mérito de crear un mercado para las maderas tropicales mexicanas, en realidad éstas —en particular, el cedro y la caoba, a más del palo de tinte- se convirtieron en mercancías de exportación en el transcurso del siglo xIx, orientadas a la fabricación de muebles finos. Por otra parte, en la región que nos ocupa, el corte de cedro rojo para la producción de durmientes fue muy común entre 1930 y 1940 , pero a reducida escala (Capdepont, 2008: 14; AGEY, fondo: municipios, sección: Tizimín, caja 1, vol. 2, exp. 7, 1941-1942, fojas varias).

${ }^{15}$ Entrevistas con L. N. y M. C., Colonia Yucatán, julio de 2012. El sitio donde se estableció esta sierra fue, de hecho, el primer asentamiento industrial maderero de Medina, lugar al que se denominó precisamente La Sierra, a sólo $1 \mathrm{~km}$ de lo que llegó a ser Colonia Yucatán.

${ }^{16}$ Desde los primeros años, Medina estuvo asociado a empresarios yucatecos vinculados a la producción de henequén, entre ellos José Vales Guerra, Arturo Millet y su propio hermano Héctor. De hecho, los fondos que hicieron posible la industrialización de la maderera provinieron de la participación de inversionistas agrupados en sociedades anónimas, las cuales fueron derivaciones de las operaciones principales de Medina, entre quienes figuraba también un importante componente de capitales extranjeros, sobre todo británicos y norteamericanos (Medina Vidiella, 1972; sin autor, 1950: 12).
} 
sistemas de prensas, guillotinas, sierras, secadoras y lijadoras, movilizadas mediante una planta de fuerza a vapor que funcionaba con el agua de un cenote. Las grúas, tractores, camiones y la vía marítima sustituyeron al tren y la tracción animal.

Con estos pasos las actividades de la empresa maderera se centraron en lo que, en los años siguientes, se convirtió en su vocación principal, a saber, la fabricación de triplay o contrachapado - producto que consistía en el ensamble de tablas o chapas de madera mediante resinas, algunas veces con acabados que formaban figuras y motivos decorativos-, que se utilizaba en la construcción de muebles y puertas, y como insumo para la construcción de casas, al igual que otros productos acabados como duelas y lambrines.

Este proceso de industrialización posibilitó que la empresa arrojara una de las producciones madereras más importantes a nivel nacional. Así, en 1950, la década de mayor apogeo en la producción maderera en manos de Medina, el valor de la explotación forestal de Yucatán era de 2.9 millones de pesos, lo cual representaba el 6.6\% del valor nacional, para ascender en 1957 a 9.7 millones, es decir, el $12.9 \%$ de dicho valor. ${ }^{17}$ El próspero negocio maderero se mantuvo así hasta fines de los años sesenta, cuando, entre otros factores, el agotamiento de los cedros determinó la utilización de leña y "maderas corrientes" para la fabricación de aglomerados de bajo costo.

Por su parte, durante los primeros años de la industria salinera de Las Coloradas, la producción y recolección del mineral estuvieron basadas en métodos poco tecnificados. Cientos de trabajadores recolectaban manualmente la sal de los charcos salinos, utilizando implementos como palas y cestos de bejuco. Los charcos eran explotados en su estado natural, y la cosecha de la sal se sujetaba a las estaciones, realizándose especialmente en los tiempos de secas.

Esta forma de obtener la sal fue modificándose gradualmente, sobre todo a partir de los años cuarenta, cuando tuvo lugar el primer proceso de mecanización de la actividad, favorecido, como ya mencionamos, por los préstamos y asociaciones conseguidos por los hermanos Roche. En esos años los empresarios procuraron la construcción de varios estanques de evaporación y sistemas de bombeo para agilizar la cristalización del mineral, y también edificaron plantas para el lavado y la refinación de la sal (Roche, 1998: 326-328). Estos procesos de modernización, sin embargo, sólo afectaron la producción bruta de sal, ya que los trabajos de la cosecha continuaron siendo fundamentalmente manuales hasta mediados de la década de los años setenta.

En los años sesenta tuvo lugar una importante transformación del paisaje salinero de Las Coloradas, con la construcción de numerosas salinas artificiales y estanques. Otras salinas fueron ampliadas, y se desarrollaron más obras hidráulicas orientadas a provocar la rápida cristalización de la sal. Pero, al igual que

\footnotetext{
${ }^{17}$ FRRM, Estudio económico de Yucatán y Programa de trabajo, Gobierno del Estado de Yucatán, Mérida, 1961: 24.
} 
durante los años anteriores, las innovaciones para la cosecha de sal fueron menos importantes, ya que únicamente se introdujo una pequeña cosechadora mecánica que no logró desplazar a la cosecha manual de sal en su totalidad (Fraga, 1999: 264). Tampoco se hicieron mayores modificaciones en el procesamiento del mineral o en sus acabados. Aunque estos procesos de tecnificación fueron considerables, las mayores obras se concretaron en varios momentos a partir de fines de los años setenta, cuando también se introdujeron cosechadoras mecánicas que sustituyeron, en su totalidad, a los cosechadores manuales de sal.

Más allá de sus particularidades, un elemento importante relacionado con la industrialización de Las Coloradas y de Colonia Yucatán tiene que ver con que el poblamiento de los dos lugares fue concomitante a tales procesos. Al industrializarse, los asentamientos iniciales se convirtieron en instalaciones fabriles estables, sin que para ello obstara el hecho de que otras labores, como la obtención bruta de maderas y la recolección del mineral, continuaron siendo temporales, al seguir dependiendo de los eventos climatológicos. Desde las racionalidades de los patrones, la construcción de asentamientos permanentes hacía imperativa la implementación de órdenes sociales que reglamentaran no sólo el trabajo en las industrias, sino también la vida de los poblados en expansión.

\section{Pueblos-empresa. Organización social}

Las formas de organización social que se consolidaron en Las Coloradas y Colonia Yucatán entre 1940 y 1970 —que aquí hemos caracterizado como propias de los pueblos-empresa - fueron semejantes en muchos aspectos, principalmente porque ambas estaban dirigidas a maximizar el uso del esfuerzo humano, reducir las posibilidades de organización colectiva de los trabajadores y habitantes, y mantener el dominio de los patrones sobre los principales recursos del lugar. La exposición de los rasgos particulares de dicho sistema permitirá ahondar en la problematización de la conformación de la microrregión salinera forestal en la montaña.

Por principio de cuentas, fijémonos en los factores que intervinieron en el surgimiento de estas formas de organización en las dos poblaciones.

Un elemento central en la conformación de los dos pueblos-empresa lo constituyeron sus formas de poblamiento. La ausencia de población originaria en los espacios donde se asentaron las operaciones principales de las dos empresas determinó el imperativo traslado de trabajadores para el comienzo de las actividades. Con el propósito de atraer mano de obra, los empresarios Medina y Roche implementaron los mismos sistemas de trabajo que habían predominado en la montaña desde mediados del siglo xIX, especialmente el campamento y el enganche.

Los campamentos eran asentamientos provisionales que consistían en un conjunto de viviendas endebles — conocidas como hatos- únicamente destinadas a cubrir de manera temporal las necesidades básicas de alimentación y reposo 
de los trabajadores. En buena medida, lo efímero de los asentamientos se relacionaba con la estacionalidad de las actividades, pues, como ya comentamos, la obtención bruta de sal y el corte de maderas se realizaban únicamente en tiempos de secas. Conviene apuntar aquí que los campamentos también fueron centrales en la chiclería, la otra explotación importante en la montaña, llevada a cabo en temporada de lluvias.

Conforme la industrialización de los procesos productivos avanzaba y los recintos fabriles se hacían permanentes, los trabajadores que comenzaban a especializarse en la operación de la maquinaria se convertían también en habitantes fijos de los nuevos asentamientos y poco a poco llevaban con ellos a sus familias (esposa e hijos). Estos fueron pasos decisivos en la transformación de los campamentos en poblaciones estables.

Por su parte, el enganche era una forma de reclutamiento de trabajadores asociada al campamento, que constituía el mejor medio para garantizar su traslado hasta la lejana montaña. El enganche funcionó lo mismo para la sal que para el corte de maderas preciosas, la producción de chicle y el palo de tinte. Consistía en el pago por adelantado de una cantidad considerable de dinero (que podía oscilar entre los 100 y los 300 pesos plata en la década de 1930) con la cual el trabajador se comprometía a ir al lugar de trabajo y permanecer en él hasta saldar, con su labor, la cantidad anticipada. El enganche estuvo presente en los comienzos del corte de maderas en manos de Medina y también en Las Coloradas, si bien en este último lugar el reclutamiento de los trabajadores no cubría propiamente un pago anticipado, sino simplemente los gastos del difícil traslado hacia el pueblo y la alimentación.

Aunque estas dos formas de organización del trabajo social —el campamento y el enganche- dinamizaron los movimientos de población en la montaña decimonónica, en el siglo xx los ejidos se convirtieron en el recurso más importante para la colonización de la región. La Reforma Agraria y los proyectos de colonización emprendidos por el Estado mexicano para el poblamiento del oriente de Yucatán y del territorio de Quintana Roo propiciaron la creación de numerosos poblados nuevos a finales de los años treinta y, sobre todo, en la década de 1960; algunos de ellos fueron formados sobre antiguos campamentos o pueblos indígenas. En ese sentido, el que Las Coloradas y Colonia Yucatán se hubieran poblado completamente a partir de sistemas que en otro tiempo fueron propios de la región pero que entraban en desuso es un factor que podemos considerar decisivo en la especificidad de su conformación social como microrregión en la montaña.

Ciertos imaginarios de la lejanía y el despoblamiento subyacían a estos procesos, ya que para los empresarios salineros y forestales fueron justificaciones importantes del grado de dominio que llegaron a establecer sobre la población. Estos imaginarios describían a los espacios salinero y forestal como enclavados en montes inaccesibles, incomunicados, que constituían márgenes de la legalidad y civilización, como se aducía desde la Guerra de Castas. Por ejemplo, recordando 
su llegada a la montaña, Alfredo Medina Vidiella la describía como: "una región de la que sólo se hablaba por los crímenes de chicleros y por los piquetes de las cuatro narices" (Medina Vidiella, 1972). Y los hermanos Roche, por su parte, hablaban de la costa oriental como un espacio tan desconocido, que tuvo que ser "descubierto" tras una larga travesía (Roche, 1988: 325). Éste es un marco de sentido compartido incluso por los primeros trabajadores. Muchos de ellos relatan con gran detalle las múltiples dificultades que habían de sortear para llegar a los trabajos de la sal y la madera, y como señalaremos adelante, estas apreciaciones se convirtieron en recursos centrales para el ejercicio del autoritarismo patronal.

Entre otros, estos dos procesos - la reutilización moderna de antiguas formas de trabajo y la persistencia de antiguos imaginarios- fueron bases relevantes para la construcción de los sistemas de control social tipo pueblo-empresa que ordenaron la vida y el trabajo en Colonia Yucatán y Las Coloradas.

Aunque los órdenes sociales tipo pueblo-empresa que predominaron en las dos poblaciones tenían sus singularidades, consideramos que ambas se construían con base en el mismo esquema, el cual combinaba un sistema corporado de organización social con una economía moral. Respecto al primer elemento, siguiendo las ideas de Erving Goffman (2001 [1961]), al hablar de sistema corporado nos referimos a que en las dos poblaciones todas las formas de interacción social se daban en torno a una sola institución, en ambos casos una empresa capitalista. Era notable la ausencia de formas de relación social que no fueran las trazadas y permitidas por los patrones, quienes mantenían esta circunstancia a través del ejercicio de una enérgica vigilancia sobre las acciones de los trabajadores y demás habitantes. Además, la mayor parte de las interacciones sociales se daban entre personas que no solamente compartían los espacios laborales, sino también muchos ámbitos de la vida diaria fuera de ellos. Por otra parte, en relación con la economía moral, seguimos las ideas de E. P. Thompson (1979) y de James Scott (1977), y nos referimos al establecimiento de acuerdos sociales entre patrones y obreros, a través de los cuales se definen los límites permitidos de la explotación, a menudo poniendo en juego creencias y emociones mediante las cuales los asuntos económicos son tratados de manera no monetaria. Veamos, a continuación, algunas características de estos órdenes sociales. ${ }^{18}$

\footnotetext{
${ }^{18}$ Nos parece que, desde cierto ángulo, también podríamos referirnos a estas poblaciones como instituciones totales, en el sentido acuñado por el mismo Goffman en su libro Internados (2001 [1961]). Goffman define a la institución total como el nicho social en el que todas las relaciones entre los individuos se reducen a él, y son reguladas por poderes ajenos a ellos mismos. Sin embargo, debido al énfasis de este autor sobre sujetos como los presos o los enfermos mentales (en el sentido de que constituyen una especie de sector "peligroso" para la sociedad, a la cual busca protegerse mediante su reclusión), preferimos no utilizar este término. Por otro lado, el concepto de lo corporado también es utilizado por Eric Wolf (1957) en su tipología del campesinado latinoamericano, si bien está claro que los rasgos de las dos poblaciones que estudiamos aquí difieren radicalmente de los pueblos a los que se refiere Wolf.
} 
En cuanto al sistema corporado, a través de mayorales y administradores — que asumían las principales responsabilidades de organización de las labores y la vida en las dos poblaciones-, los patrones procuraban que solamente quienes tuvieran un trabajo en las empresas ingresaran a, y permanecieran en, la población, excluyendo a quienes no lo tuvieran o a quienes quedaran desempleados. Para ello frecuentemente entraban en juego ciertos recursos discursivos, como las afirmaciones de que "éste es un lugar de trabajo", o "aquí nadie viene a pasear", encontradas con notable recurrencia entre los primeros pobladores de Colonia Yucatán y de Las Coloradas. Con el mismo propósito los patrones se valían de las condiciones de lejanía y de difícil acceso que se imponían en las dos poblaciones, relacionadas precisamente con su ubicación en una zona apenas civilizada. Así, durante varios años la única forma de llegar a las dos poblaciones fue mediante el traslado proporcionado por los patrones, debido a la carencia de caminos o a su mal estado, y a la falta de transporte público que llevara a ellas. ${ }^{19}$ Incluso, los patrones habían conseguido que solamente ingresaran a los pueblos quienes contaran con autorizaciones escritas, emitidas por ellos mismos. Estas condiciones producían un profundo cierre social en las dos poblaciones.

La falta de alternativas ocupacionales más allá de las que proporcionaban las industrias, contribuía al cierre social de las dos poblaciones, ya que la situación de quedarse desempleado, sea por despido o por haber desarrollado actividades temporales, era el criterio central que definía la imposibilidad de permanencia en los dos lugares. Aunque la pesca y la agricultura pudieron haber sido actividades complementarias a los trabajos de la madera y de la sal, en realidad no se desarrollaron sino hasta más tardíamente. ${ }^{20}$ De hecho, la presencia de ciertas antipatías entre los trabajadores de la fábrica maderera y los campesinos solicitantes de ejido en los alrededores, y entre los obreros de la industria salinera y las emergentes agrupaciones de pescadores, sobre todo del vecino pueblo de Río Lagartos, pueden considerarse sedimentaciones ideológicas de la centralidad de las empresas en la vida social de ambos pueblos.

La casi total ausencia de formas de organización social "desde abajo" —es decir, no trazadas por los empresarios - es un aspecto más de este orden corporado en el que los patrones regían la organización social de las dos poblaciones. Una de las concreciones más relevantes de ello es que hasta 1965 en Colonia Yucatán, y 1980 en Las Coloradas, los trabajadores carecieron de cualquier forma de representación obrera o sindical.

Aunque más allá del espacio fabril los trabajadores y sus familias tenían diversas formas de convivencia, particularmente relacionadas con el esparcimiento,

${ }^{19}$ En Las Coloradas el transporte público comenzó a funcionar hasta 1980, mientras que en Colonia Yucatán desde la década de 1960 existían camionetas particulares que proporcionaban el servicio, por lo que su comunicación por tierra era más óptima que la del pueblo salinero, si bien era poco frecuente y de duración prolongada.

${ }^{20}$ En Colonia Yucatán y sus alrededores la agricultura ejidal comenzó a desarrollarse a mediados de los años setenta, mientras que en Las Coloradas la pesca organizada inició a fines de 1980. 
también éstas eran organizadas por los patrones. Así, el llamado casino de Las Coloradas y el boliche, billar y cinema de Colonia Yucatán, eran propiedad de los empresarios, parcialmente concesionados a pequeños comerciantes yucatecos. Y aunque también había grupos deportivos diversos, sumamente apreciados por los trabajadores, igualmente eran organizados por los patrones. Dadas estas condiciones no sorprende que muchos trabajadores describieran su vida durante estos años como una especie de encierro. Un obrero de la fábrica maderera relató lo siguiente: "no teníamos oportunidad de hacer nada, aquí puro trabajar; yo trabajaba de 12 de la noche hasta las 5 de la tarde del otro día”, mientras que un trabajador de Las Coloradas señalaba: "era como una especie de cautiverio, porque llegas acá, sólo trabajas, sales de tu trabajo, vienes a tu casa, es una vida muy rudimentaria”.

En este renglón hay que destacar que los diversos modelos de familia y los compadrazgos de los trabajadores constituían lazos sociales que, si bien no eran trazados por los patrones, apenas tuvieron impacto en la negociación de las condiciones de vida de los trabajadores, al menos durante el periodo de mayor predominio de estos sistemas. ${ }^{21}$ Esto a diferencia de lo que ocurría en otros pueblos de la montaña, sobre todo los de raigambre indígena, donde los arreglos familiares y las formas mayas de gobierno constituían la base de la organización social.

Un importante soporte de este orden corporado lo constituía la presencia constante de destacamentos militares o de la marina, al igual que guardias forestales, que aunque no eran directamente controlados por los patrones sí obedecían a sus intereses. Estas entidades ejercían labores continuas de vigilancia sobre los habitantes, y mediante la intimidación buscaban contener altercados o sabotajes a las operaciones empresariales, pero sobre todo limitaban enérgicamente todo tipo de organización de los trabajadores y sus familias. Según la memoria colectiva de los habitantes de Las Coloradas, un destacamento militar perseguía continuamente cualquier forma de agrupación, como las reuniones realizadas en torno a la devoción evangélica que varias familias profesaban, e incluso los encuentros ocasionales para platicar en la calle o en las casas. Por su parte, en Colonia Yucatán muchos antiguos habitantes relatan la presencia continua de la "federación" y de la "judicial" con el propósito de mantener el orden del pueblo, y también atestiguan la posibilidad de detención o de llamada de atención si alguna persona circulaba a "horas indebidas", es decir, después de las 10 de la noche. La persecución al corte ilícito de maderas y al contrabanado

${ }^{21}$ Conviene relativizar aquí esta apreciación, ya que entre 1979 y 1980 tuvo lugar en Las Coloradas un genuino movimiento obrero que pugnaba por la mejora en las condiciones de vida y de trabajo en el pueblo, culminando en la conformación de un sindicato de trabajadores, vigente hasta la actualidad. La conformación de este movimiento fue posible, precisamente, gracias a la organización de los trabajadores y sus familias a través de vínculos de parentesco, vecindad y población de origen. Excluimos del análisis este proceso ya que tomó lugar justo cuando las condiciones de pueblo-empresa comenzaron a transformarse, y la cerrazón social en este pueblo tendió a desaparecer en algunos aspectos. 
era una de las principales justificaciones para implementar estos dispositivos de vigilancia, y el fenómeno recuerda la ocupación militar que, desde la primera década del siglo xx, había trazado la relación del Estado mexicano con la montaña.

En cualquier caso, la vigilancia cotidiana con fines de intimidación constituía un efectivo recurso que durante un largo periodo mantuvo las condiciones de cierre social en las dos poblaciones. Estas formas de vigilancia, más que una práctica ideológica, constituían un manejo coercitivo de la vida social.

Y, en fin, un rasgo más del sistema corporado que predominó en las dos poblaciones - que permite introducirnos a la composición de sus economías moralesera el hecho de que los patrones centralizaban el aprovisionamiento de toda la infraestructura urbana y la dotación de los elementos básicos para la sobrevivencia. Las viviendas de los trabajadores, el suministro de bienes de consumo para el abasto cotidiano, el agua potable, la energía eléctrica, los templos — sólo permitidos los consagrados a la devoción católica-, el comercio, el ordenamiento del espacio y las escuelas para la instrucción básica (jardín de niños y primaria) eran ámbitos proporcionados y reglamentados por los patrones. También los servicios médicos estuvieron inicialmente en sus manos, si bien en ambos casos a mediados de los años sesenta pasaron a ser administrados por el Instituto Mexicano del Seguro Social (IMSS). Es decir, tampoco en lo concerniente a la dotación y regulación de estos elementos, claves para la subsistencia de los pobladores, podían penetrar entidades ajenas a las industrias y al sector patronal.

Refiriéndonos ahora a las economías morales de Las Coloradas y Colonia Yucatán, su principal rasgo era que se sustentaban en el otorgamiento de ciertas dádivas, por parte de los patrones, las cuales contribuían a matizar la explotación desmedida del trabajo y las condiciones de cierre social ya mencionadas, y que hacían posible que problemas de orden económico, como el salario y el costo de la subsistencia, fueran tratados de forma no económica.

Como introducción a este tema es preciso mencionar una característica común a las dos industrias: el uso desmedido del trabajo y la exposición a diversos riesgos. En los dos pueblos las jornadas laborales abarcaban mínimamente doce horas, con un día semanal de descanso que era opcional, ya que en las fábricas "siempre había trabajo". A ello hay que añadir que los trabajadores desempeñaban oficios sumamente precarios y riesgosos - en los dos casos ocasionados por las exigencias de un trabajo realizado a destajo-, que en la industria maderera podían ocasionar mutilaciones y fatalidades subsecuentes, y en la industria salinera, escoriaciones, ampollas e infecciones originadas por la exposición continua a los granos de sal. ${ }^{22}$ Los ataques de la fauna de la zona - como lagartos, jaguares, serpientes, monos y mosquitos- eran parte de la precariedad de vivir en estas dos poblaciones. De modo que, frente a estas circunstancias, parecía nece-

${ }^{22}$ En Colonia Yucatán, según los propios registros de su servicio médico, entre 1945 y 1951 se presentaron 772 accidentes, de los cuales 16 resultaron en defunciones, sin tener mayor información sobre mutilaciones y otros accidentes que resultaron en hombres incapacitados de por vida (Ríos Macbeth, 1951). 
sario crear otro tipo de relación con los obreros que garantizara su permanencia y su trabajo continuo, más allá de la compensación monetaria, pero sobre todo que trazara un nivel mínimo de subsistencia, aceptable en ese difícil entorno.

Ya hemos mencionado que los patrones proporcionaban todos los bienes y servicios para la subsistencia de los trabajadores, gratuitos o a bajo costo, en comparación con los precios de los mercados regionales. Este elemento fue una pieza fundamental del funcionamiento de la economía moral en las dos poblaciones. En Colonia Yucatán, a través de la tienda de consumo los patrones otorgaban a los trabajadores mercancías para la alimentación (como café, leche en polvo, maíz, frijol y azúcar), lo cual constituía una especie de salario indirecto, ya que el costo de lo consumido durante la semana se les descontaba de su paga. Muchas personas consideraban que este sistema era una importante evidencia de la genuina preocupación de los patrones por el bienestar de su personal y sus familias, pues de esa forma se garantizaba la buena alimentación de todos, problema importante ante la pobreza generalizada en muchos pueblos de Yucatán. En Las Coloradas, por su parte, durante los primeros años los patrones proporcionaban una comida fuerte al día a los trabajadores, que estos pagaban con determinadas cantidades semanales de sal. Posteriormente, esta ayuda se eliminó conforme los patrones consiguieron que un par de comerciantes de Tizimín llevaran mercancías (carne, frutas y verduras) al pueblo una vez a la semana, hecho que fue positivamente apreciado por los obreros, quienes lo observaron como un favor patronal dadas las condiciones de aislamiento del asentamiento.

La situación de la vivienda era otro ámbito sobre el que se sostenían las economías morales de las dos poblaciones. Aunque los patrones eran dueños de las casas donde los trabajadores y sus familias residían, éstos se sentían agradecidos de que no tuvieran que pagar renta ni ningún otro gasto que devengara el habitarlas, ya que incluso su reparación corría a cargo de los patrones. El abasto cotidiano de agua potable y de energía eléctrica —en horarios limitados-, como ya mencionamos, era parte de los recursos cubiertos por los patrones al otorgar habitación a los trabajadores. El que el acceso a ellos fuera visto por los trabajadores como un favor patronal, y no como un derecho, era una dimensión más del funcionamiento de la economía moral.

El trato que los patrones daban a asuntos estrictamente monetarios es otro aspecto de este sistema. Por ejemplo, en Colonia Yucatán algunos trabajadores señalan que cuando iban a recibir su salario semanal podían ser disuadidos de cobrarlo en su totalidad con el argumento de que debían ahorrarlo y no derrocharlo. Lo mismo ocurría en Las Coloradas, cuando a fin de año los patrones otorgaban a los trabajadores una pequeña compensación monetaria a modo de aguinaldo, que era entregada personalmente por ellos mismos, conminando a los trabajadores a darle un buen uso. De esta forma, los patrones no solamente buscaban limitar la agencia de los obreros sobre sus propios ingresos, sino también colocarse como figuras con un amplio control sobre las decisiones de sus empleados. 
Este tipo de prácticas encontraba su soporte en ciertos recursos simbólicos. Uno de ellos, particularmente relevante en Colonia Yucatán, era la consideración del patrón como un padre que tenía que encauzar el crecimiento de los hijos; como mencionaba un trabajador, "con Medina Vidiella se llevó a cabo que nosotros fuéramos hijos de familia de la casa del señor, por que él aquí era un poderoso". Esta apreciación era asumida por el mismo Medina, quien, en un discurso en 1972, al defenderse del paternalismo que se le imputaba, decía: "éramos una gran familia... ipuede existir una familia decente sin un buen padre? Yo creo que no".

En Las Coloradas, por su lado, fueron más relevantes ciertas apreciaciones centradas en la "confianza" de los patrones hacia algunos de los trabajadores y la amistad personal —esto es, las "buenas relaciones"-, ya que muchas personas consideraban que éstos eran los únicos medios para acceder a ciertas mejorías en sus condiciones de vida, como la promoción laboral, préstamos monetarios o la reparación de sus viviendas, entre otras prerrogativas. Las negociaciones individuales, generalmente consideradas como favores personales, eran el principal referente de estas apreciaciones.

La eficacia de estos sistemas de organización social es indiscutible. Mediante ellos los empresarios Medina y Roche aseguraron la permanencia de una amplia cantidad de trabajadores, dedicados exclusivamente a los trabajos de la madera y la sal, y sobre todo consiguieron encarnar la única autoridad en Colonia Yucatán y Las Coloradas hasta fines de 1960 y 1980, respectivamente.

A partir de estos momentos diversos procesos condujeron a la paulatina declinación del cierre social de las dos poblaciones en torno a las empresas. En el caso de Colonia Yucatán, la pujanza de una enérgica reforma agraria, que se llevó a cabo en antiguos terrenos de la empresa maderera; la salida del empresario Medina de la administración de la misma y la conformación de un sindicato, fueron algunos de los procesos que coadyuvaron a la apertura de la población y a la entrada de nuevas corrientes ideológicas. En Las Coloradas el hartazgo obrero que cuajó en la formación de un sindicato y la llegada de nuevos actores al pueblo -algunos de ellos luchaban por integrarse a las organizaciones pesqueras fomentadas por el estado, y otros por integrar fieles a diversos cultos no católicos- contribuyeron también en ese sentido.

\section{BIBLIOGRAFÍA}

Sin autor

1999 "Alfredo Medina", Yucatán en el tiempo, enciclopedia alfabética, vol. 4, pp. 130131. Mérida: Cares.

Sin autor

1950 "El desarrollo de la industria maderera en Yucatán”, Frente a la selva, 2 (1). 
Bracamonte y Sosa, Pedro

2001 La conquista inconclusa de Yucatán. Los mayas de la montaña: 1560-1680. México: Centro de Investigaciones y Estudios Superiores en Antropología Social.

Boyer, Christopher R. y Lucrecia Orensanz

2007 "Revolución y paternalismo ecológico: Miguel Ángel de Quevedo y la política forestal en México,1926-1940”, Historia Mexicana, 57 (1): 91-138.

Capdepont Ballina, Jorge Luis

2008 "Con la furia de las sierras cayeron las caobas y se fue nadando la selva. Las monterías en las sierras de Tabasco y Chiapas (1855-1936)", tesis de Doctorado en Historia. Zamora: El Colegio de Michoacán.

Demmers, Jolle

1998 Friends and Bitter Enemies. Politics and Neoliberal Reform in Yucatán, México. Amsterdam: Thela Thesis.

Forero, Oscar y Michael R. Redclift

2006 "The Role of the Mexican State in the Development of Chicle Extraction in Yucatán, and the Continuing Importance of Coyotaje", Journal of Latin American Studies, 38 (1): 65-93.

Fraga Berdugo, Julia

1999 "Política ambiental y relaciones de género en un área natural protegida: la relación global/local en Río Lagartos, México", tesis de Doctorado en Antropología. Quebec: Université Laval.

Garibay, Claudio

2008 Comunalismos y liberalismos campesinos. Identidad comunitaria, empresa social forestal y poder corporado en el México contemporáneo. Zamora: El Colegio de Michoacán.

Goffman, Erving

2001 Internados. Ensayos sobre la situación social de los enfermos mentales. Buenos Aires: Amorrortu.

Konrad, Herman W.

1987 "Capitalismo y trabajo en los bosques de las Tierras Bajas tropicales mexicanas: el caso de la industria del chicle”, Historia Mexicana, 36 (3): 465-505.

Macías, Gabriel

2004 "Estudio introductorio", El vacío imaginario. Geopolítica de la ocupación territorial en el Caribe oriental mexicano, pp. 11-46, G. Macías (coord.). México: Centro de Estudios Superiores en Antropología Social / H. Congreso del Estado de Quintana Roo.

Macías Richard, Carlos

1999 "El territorio de Quintana Roo. Tentativas de colonización y control militar en la selva maya (1888-1902)”, Historia Mexicana, 49 (1): 5-54. 
Medina Vidiella, Alfredo

1950 "Quince años de trabajo", Desde la selva, 7 (1).

1972 Sin título. Discurso pronunciado en la inauguración del jardín de niños de Colonia Yucatán. Disco de acetato inédito.

Ríos Macbeth, Daniel

1951 "Las enfermedades en la selva", Desde la selva, 7 (1).

Roche Díaz, Joaquín

1998 "Producción y comercialización de la sal en la Península de Yucatán", La sal en México, vol. II, Juan Carlos Reyes D. (comp.). Colima / México: Gobierno del Estado de Colima / Universidad de Colima / Consejo Nacional para la Cultura y las Artes.

Sariego, Juan Luis

1988 Enclaves y minerales en el norte de México. México: Centro de Investigaciones y Estudios Superiores en Antropología Social.

Scott, James

1977 The Moral Economy of the Peasant: Rebellion and Subsistence in Southeast Asia. New Haven: Yale University Press.

Secretaría de Economía

1933 Estudio sobre la sal. México: Secretaría de Economía.

Thompson, E. P.

1979 Tradición, revuelta y conciencia de clase. Estudios sobre la crisis de la sociedad preindustrial. Barcelona: Crítica.

Villalobos, Martha

1993 "Las concesiones forestales en Quintana Roo a fines del porfiriato", Relaciones, XIX (53): 87-112.

Wolf, Eric

1957 "Closed Corporate Peasant Communities in Mesoamerica and Central Java”, Southwestern Journal of Anthropology, 13 (1): 1-18.

Zapata, Francisco

1977 "Enclaves y sistemas de relaciones industriales en América Latina”, Revista Mexicana de Sociología, 39 (2): 719-731.

\section{FUENTES DOCUMENTALES}

AGA (Archivo General Agrario)

"Memorandum relativo a la unidad industrial de explotación forestal que opera en la peninzula de Yucatán, 6 de abril de 1959, Mérida Yuc.” Oficina de Yucatán, exp. 23-580, poblado: Colonia Yucatán, 1959, asunto: dotación. 
AGEY (Archivo General del Estado de Yucatán)

"Diligencias de jurisdicción voluntaria promovidas por Héctor Medina Vidiella, para que se ordene judicialmente la inscripción en el Registro Público del Comercio, de la escritura pública de prórroga de plazo y ampliación de capital de la sociedad denominada 'Maderas de Yucatán, S. A.”' Fondo: poder judicial 1840-1966, sección: primer depto., serie: juzgado 2o de lo civil, caja 274 , vol. 274, exp. 8091, 1941.

"Carta de Rodolfo Lara Vega al jefe de la Oficina Federal de Hacienda", 16 de junio de 1942. Fondo: Municipios, sección: Tizimín, caja 1, vol. 2, exp. 11, 1942, foja 19. Fondo: Municipios, sección: Tizimín, caja 1, vol. 2, exp. 7, 19411942 , fojas varias.

FRRM (Fondo Reservado “Rodolfo Ruz Menéndez”)

Gobierno del Estado de Yucatán, Estudio económico de Yucatán y Programa de trabajo, Mérida, 1961.

\section{HEMEROGRAFÍA}

Diario Oficial de la Federación

1933 "Acuerdo que declara como reserva nacional para la explotación de cloruro de sodio las salinas de las costas del Golfo de México y del Océano Pacífico", 26 de septiembre.

Diario Oficial de la Federación

1935 "Acuerdo que concede autorización para contratar con sociedades cooperativas la explotación de las salinas declaradas de reserva nacional”, 8 de junio.

Diario Oficial de la Federación

1949 "Decreto que establece en favor de Maderas del Trópico S. A. y Maderas Laminadas S. A. una Unidad Industrial de explotación forestal con los límites que el mismo especifica", 28 de julio. 